\title{
Effects of different heat treatments on lysozyme quantity and antimicrobial activity of jenny milk
}

\author{
C. Cosentino, ${ }^{1}$ C. Labella, H. S. Elshafie, I. Camele, M. Musto, R. Paolino, C. D’Adamo, and P. Freschi \\ School of Agricultural, Forest, Food, and Environmental Sciences, University of Basilicata, Viale dell'Ateneo Lucano 10, 85100 Potenza, Italy
}

\section{ABSTRACT}

Thermal treatments are used to improve milk microbial safety, shelf life, and biological activity of some of its components. However, thermal treatments can reduce the nutritional quality of milk, affecting the molecular structure of milk proteins, such as lysozyme, which is a very important milk component due to its antimicrobial effect against gram-positive bacteria. Jenny milk is characterized by high lysozyme content. For this reason, in the last few years, it has been used as an antimicrobial additive in dairy products as an alternative to hen egg white lysozyme, which can cause allergic reactions. This study aimed to investigate the effect of pasteurization and condensation on the concentration and antimicrobial activity of lysozyme in jenny milk. Furthermore, lysozyme quantity and activity were tested in raw and pasteurized milk after condensation at 40 and $20 \%$ of the initial volume. Reversed-phase HPLC was performed under fluorescence detection to monitor lysozyme in milk samples. We evaluated the antimicrobial activity of the tested milk against Bacillus megaterium, Bacillus mojavensis, Clavibacter michiganensis, Clostridium tyrobutyricum, Xanthomonas campestris, and Escherichia coli. Condensation and pasteurization did not affect the concentration or antimicrobial activity of lysozyme in jenny milk, except for B. mojaventis, which showed resistance to lysozyme in milk samples subjected to heat treatments. Moreover, lysozyme in jenny milk showed antimicrobial activity similar to synthetic antibiotics versus some gram-positive strains and also versus the gram-negative strain X. campestris. Key words: condensation, pasteurization, lysozyme, antimicrobial activity, jenny milk

Received December 1, 2015

Accepted March 27, 2016.

${ }^{1}$ Corresponding author: carlo.cosentino@unibas.it

\section{INTRODUCTION}

Heat treatment of milk is an essential step in milk processing that has been adopted by the dairy industry. Thermal processing of milk aims to prolong the shelf life and improve the quality of this complex biological fluid by reducing the microbial load (Raikos, 2010). In other cases, if milk is used as a food ingredient in milkbased products, heat treatment is employed to improve the organoleptic properties of such dairy formulations by manipulating the functionality of milk proteins (del Angel and Dalgleish, 2006). One of the most common milk thermal treatments is pasteurization. The main aims of pasteurization are to reduce the microbial population, both pathogenic and spoilage, inactivate enzymes and minimize chemical reactions and physical changes, and to extend the milk shelf life (Gao et al., 2002).

The alteration of the food results in a change of its characteristics, such as decrease of $\mathrm{pH}$, precipitation of calcium phosphate, denaturation of whey proteins and interaction with casein, lactose isomerization, Maillard browning, and modifications to the casein micelle (Walstra and Jenness, 1984). The microorganisms that can contaminate a food are bacteria and fungi (yeasts and molds; Ledenbach and Marshall, 2009). The factors that influence their development in food are $\mathrm{pH}$, the presence or absence of oxygen, radiation, presence of chemicals, temperature, and water content (Dugenest et al., 1999). Water is essential for microorganisms; in fact, microorganisms show poor or absent growth in foods in which the water content is low (Cabral, 2010). To increase the shelf life of milk, treatments, such as lyophilization or pulverization, are applied to remove the water (Ribeiro and Ribeiro, 2010).

Polidori and Vincenzetti (2013) carried out a study on the effects of thermal treatments on jenny milk nutritional characteristics; those authors reported the enzymatic activity of lysozyme decreased up to about $70 \%$ in the powdered milk with respect to fresh and frozen milk due to the high temperatures of the atomization in the spray-dry process (up to $200^{\circ} \mathrm{C}$ ). Another technique that can be taken into account is the freeze-drying (or 
lyophilization), which is much more expensive than spray-drying but, in some cases, can lead to products of greater value (Aloisio et al., 2011). Lyophilization does not significantly affect the quality parameters of jenny milk; however, even if the enzymatic lysozyme activity does not change after lyophilization, the lysozyme concentration is slightly reduced after this thermic treatment (Vincenzetti et al., 2011).

Lysozyme is a natural antimicrobial agent that may contribute to gram-positive growth inhibition (Chiavari et al., 2005; Cosentino et al., 2012; Fratini et al., 2015). Moreover, lysozyme is able to kill or to inhibit a large spectrum of pathogens (Zhang et al., 2008; La Torre et al., 2010). Lysozyme is a natural antimicrobial agent because it catalyzes the hydrolysis of glycosidic bonds of mucopolysaccharides in bacterial cell walls. Lysozyme may work synergistically with lactoferrin and immunoglobulins in antimicrobial activity (Lönnerdal, 1985). This enzyme, along with other factors including immunoglobulins, lactoferrin, and lactoperoxidase, may limit the migration of neutrophils into a damaged tissue by behaving as an anti-inflammatory agent (LeónSicairos et al., 2006).

The lysozyme content is higher in jenny milk [from 1.0 to $3.7 \mathrm{mg} / \mathrm{mL}$, according to Zhang et al. (2008) and Galassi et al. (2012)], than in other species [cow: 0.13 $\mu \mathrm{g} / \mathrm{mL}$ (Shahani et al., 1973); ewe: $0.20 \mu \mathrm{g} / \mathrm{mL}$ (Fratini et al., 2006); goat: $0.25 \mu \mathrm{g} / \mathrm{mL}$ (Scharfen et al., 2007)]. In the recent years, some authors have proposed the use of lysozyme from jenny milk as a substitute of hen egg white (HEW) lysozyme, currently used as natural antibacterial additive in commercial dairy products (Cosentino et al., 2013, 2015a,b). Although the major egg allergens are ovalbumin and ovomucoid, several studies have shown that lysozyme is indeed an allergen (Frémont et al., 1997; Pérez-Calderón et al., 2007). On the contrary, lysozyme from jenny milk is not derived from a known allergenic source (Galassi et al., 2012), in fact Vincenzetti et al. (2014) presented evidence that demonstrate the hypoallergenicity of jenny milk in humans. To carry out its antimicrobial role it is important that the lysozyme quantity and activity are not lost during milk thermal treatment.

We proposed that condensation is a valid alternative to lyophilization and pulverization for decreasing the water content of the milk. Condensed milk is the product obtained by evaporating part of the water of whole milk or fully or partly skim milk (Van Den Berg, 1962). Cosentino et al. (2015c) previously showed that pasteurization and condensation do not significantly affect the total antioxidant capacity of jenny milk. The object of the current study was to investigate the effects of condensation and pasteurization on lysozyme quantity and antimicrobial activity in jenny milk.

\section{MATERIALS AND METHODS}

The research was carried out on bulk milk of 15 Martina Franca multiparous jennies, in midlactation (180 d after foaling), between 7 and 10 yr of age. Jennies were fed on ad libitum oat hay with an integration of $1 \mathrm{~kg} /$ head per day of concentrate, characterized by the following mixture: $37 \%$ flaked corn, $30 \%$ oats, $9 \%$ locust bean crushed, $8 \%$ wheat bran, $8 \%$ dehydrated alfalfa, $6 \%$ dried beet pulp, and $2 \%$ mineral and vitamin supplement. After milking, milk aliquots were immediately refrigerated at $4^{\circ} \mathrm{C}$ and transported to the laboratory, where the following chemical parameters were determined by Milkoscan FT 6000 (Foss Electric, Hillerød, Denmark): protein, fat, lactose, and DM. The effect of different levels of condensation on the lysozyme quantity and antimicrobial activity of jenny milk was evaluated on raw $(\mathbf{R})$ and on pasteurized $(\mathbf{P})$ milk. Pasteurization was performed by heating raw jenny milk to $63^{\circ} \mathrm{C}$ for $30 \mathrm{~min}$. Milk was condensed by rotary vacuum evaporation using system RV8 (IKA-Werke GmbH and Co., Staufen im Breisgau, Germany) equipped with a vacuum pump model PC 3001 Vario (Vacuumbrand GmbH, Wertheim, Germany), under the following conditions: water bath temperature $35^{\circ} \mathrm{C}$; pressure 4 $\mathrm{kPa}$; processing time 2 and $3 \mathrm{~h}$ for condensation at 40 (RC40 and PC40) and 20\% (RC20 and PC20) of the initial volume, respectively. Before determining lysozyme concentration and activity, to reconstitute the initial water volumes, $6 \mathrm{~mL}$ of MilliQ water (Millipore, Billerica, MA) was added to $4 \mathrm{~mL}$ of $\mathrm{RC} 40$ or PC40, and $8 \mathrm{~mL}$ of MilliQ water was added to $2 \mathrm{~mL}$ of RC20 or PC20. Each heat treatment was repeated 3 times using 3 different batches of jenny milk.

\section{Lysozyme Extraction}

For lysozyme extraction, a modified method of Pellegrino and Tirelli (2000) was employed. Ten milliliters of raw, pasteurized, and condensed jenny milk were mixed with $30 \mathrm{~mL}$ of $1 \mathrm{M} \mathrm{NaCl}(\mathrm{pH} 6)$. The samples were kept under magnetic stirring previously at $40^{\circ} \mathrm{C}$ for $10 \mathrm{~min}$, and then at room temperature for $1 \mathrm{~h}$. Afterward, the extract was acidified to a $\mathrm{pH} 2.2$ adding $1 \mathrm{M} \mathrm{HCl}$ to precipitate the caseins. Finally, the extracts were filtered over a paper filter and then with a $0.20-\mu \mathrm{m}$ filter (Minisart NML syringe filters in cellulose acetate; Sartorius, Gottingen, Germany).

\section{Chemicals for HPLC Analysis}

A freeze-dried lysozyme standard, Fluka/34046Vetranal, HPLC-grade acetonitrile, and trifluoroacetic 
acid were purchased from Sigma-Aldrich (St. Louis, $\mathrm{MO})$.

\section{Liquid Chromatographic Procedure}

The HPLC separation conditions were optimized to obtain adequate separation within a short retention time. To reduce elution time, a slightly adapted version of a published method was used (Pellegrino and Tirelli, 2000). The major difference introduced here was a different gradient elution using a higher percentage of acetonitrile (CAN) to speed up the elution of strongly retained compounds. Moreover, as suggested by Guarino et al. (2011), a reversed-phase HPLC column was employed. The HPLC analysis was performed using a chromatographic system, Agilent 1200 Series quaternary pump with vacuum degasser and autoinjector (Agilent Technologies, Santa Clara, CA). The chromatographic separations were run on a Synergi MAX-RP $80 \AA$ column $(150 \times 4.6 \mathrm{~mm}, 4 \mu \mathrm{m}$ particle size) from Phenomenex (Torrance, CA) with a MAX$\mathrm{RP}$ guard column $(4 \mathrm{~mm} \times 2 \mathrm{~mm}$ id). Injection volume was $20 \mu \mathrm{L}$ and flow rate was $0.8 \mathrm{~mL} / \mathrm{min}$. The mobile phase consisted of a gradient of water $(\mathrm{A})$ and $\mathrm{ACN}$ (B), both containing $0.1 \%$ trifluoroacetic acid ( $\mathrm{vol} / \mathrm{vol}$ ). Eluting conditions were $0 \mathrm{~min}, 80 \% \mathrm{~A}$, and $20 \% \mathrm{~B} ; 9$ $\min , 60 \% \mathrm{~A}$, and $40 \% \mathrm{~B} ; 15 \mathrm{~min}, 60 \% \mathrm{~A}$, and $40 \% \mathrm{~B}$; and $20 \mathrm{~min}, 80 \% \mathrm{~A}$, and $20 \% \mathrm{~B}$. Detection was carried out both by fluorescence detector (Jasco FP-2020 PlusIntelligent-fluorescence detector; Jasco, Easton, MD) set at $280 \mathrm{~nm}$ of excitation and $350 \mathrm{~nm}$ of emission. Calibration curves were acquired with known amounts of HEW lysozyme in the concentration range of 5 to $100 \mathrm{mg} / \mathrm{L}$. Five-point calibration curves were plotted as the peak area versus standard concentration, and all measurements were done in triplicate. Using the calibration curve obtained with HEW lysozyme standard solution in a range between 5 and $100 \mathrm{mg} / \mathrm{L}(5,10,20$, $50,100 \mathrm{mg} / \mathrm{L}$ ), it was possible to estimate the lysozyme concentration in jenny milk. The concentration data were calculated considering the $90 \%$ of recovery according to Pellegrino and Tirelli (2000). The linear correlation coefficient was 0.997 . Estimated limit of detection of lysozyme was $0.49 \mathrm{mg} / \mathrm{L}$. The limit of detection was evaluated as 3.3 times the standard deviation of the intercept divided by the slope (Bianco et al., 2013). Estimated limit of quantification of lysozyme was 1.5 $\mathrm{mg} / \mathrm{L}$. The limit of quantification was evaluated as 10 times the standard deviation of the intercept divided by the slope (Shrivastava and Gupta, 2011).

\section{Tested Bacterial Strains}

Some representative bacterial strains available in a range of different ecological niches (e.g., soil, vegetables, cheese, and so on) were selected either in gram-positive or gram-negative strains for evaluating the antibacterial activity of lysozyme in different treatments of jenny milk. The tested bacteria were 4 gram-positive strains (Bacillus megaterium, Bacillus mojavensis, Clavibacter michiganensis, and Clostridium tyrobutyricum) and 2 gram-negative strains (Xanthomonas campestris and Escherichia coli). All studied bacteria were cultured on King B (KB) medium (King et al., 1954), except E. coli, which was cultured on Luria Bertani (LB) selective medium (Oxoid, Milan, Italy). All bacterial cultures were incubated at $30 \pm 2^{\circ} \mathrm{C}$ for $48 \mathrm{~h}$.

\section{Antibacterial Activity Test}

The antibacterial test of studied jenny milk was carried out using disc diffusion method of Bhunia et al. (1988) with minor modifications. Bacterial suspension of each bacterial culture was prepared in sterile distilled water at concentration of $10^{8} \mathrm{cfu} / \mathrm{mL}$ (optical density $\approx 0.2 \mathrm{~nm})$. A mixture of $0.7 \%$ of soft agar and bacterial suspension $(9: 1, \mathrm{vol} / \mathrm{vol})$ was prepared and $4 \mathrm{~mL}$ of this suspension was poured into each $10-\mathrm{mL}$ KB petri dish, $90 \mathrm{~mm}$ in diameter. Blank discs $(6 \mathrm{~mm}$; Oxoid, Thermo Fisher Scientific, Waltham, MA) were placed over KBplate surfaces after complete solidification and $20-\mu \mathrm{L}$ aliquots from each samples were carefully applied over discs. For assessing the antibacterial activity of tested milk samples, 2 synthetic antibiotics, ampicillin (100 $\mu \mathrm{g} / \mathrm{mL})$ and kanamycin $(50 \mu \mathrm{g} / \mathrm{mL})$, and a solution of HEW-lysozyme $(1,000 \mathrm{mg} / \mathrm{L}$ in MilliQ water $)$ were used. The antibacterial activity of the tested milk was evaluated by measuring the inhibition zone diameter in $\mathrm{mm}$. For comparison, the antibacterial activity of the 2 synthetic antibiotics and of HEW-lysozyme were tested against the same bacterial strains. For each batch of jenny milk, the experiment was repeated 3 times with 3 replicates.

\section{Statistical Analysis}

Data on lysozyme quantification and antibacterial activity were analyzed by ANOVA. Differences among milk treatments were tested by Tukey's B post hoc multiple comparison tests.

\section{RESULTS AND DISCUSSION}

The batches of jenny milk had chemical composition (mean $\pm \mathrm{SD}$ ) of $1.72 \pm 0.03 \%$ protein, $0.16 \pm 0.03 \%$ fat, $6.42 \pm 0.01 \%$ lactose, and $12.74 \pm 0.05 \%$ DM content.

Milk is a very complex matrix, so to quantify the lysozyme a previous extraction was necessary, followed by chromatographic analysis. By way of example, Fig- 


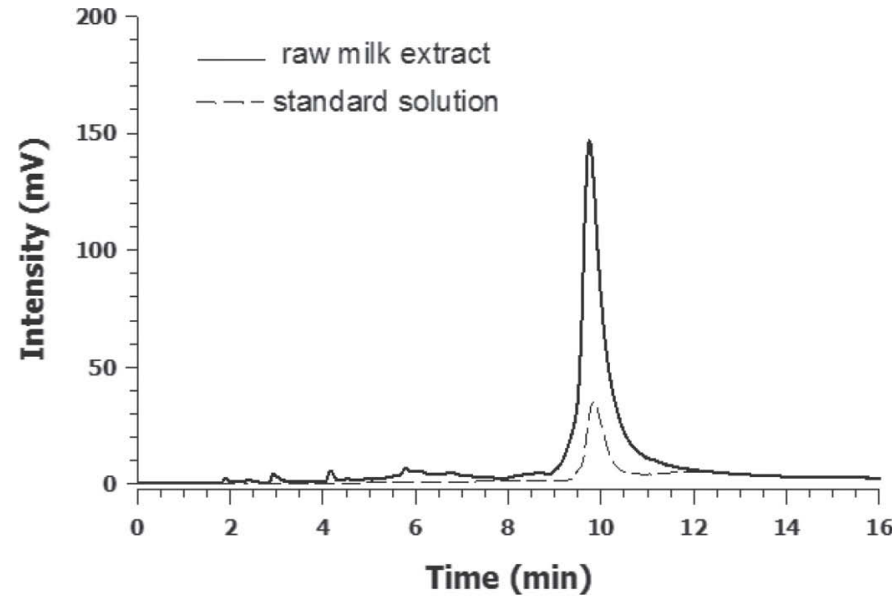

Figure 1. Chromatogram of lysozyme extract from raw jenny milk by fluorescence detector set at $280 \mathrm{~nm}$ (excitation) and $350 \mathrm{~nm}$ (emission). The dotted line is the chromatogram of hen egg white lysozyme standard solution.

ure 1 shows the chromatogram of lysozyme with fluorescence detection for raw milk (not condensed). The time retention is about $10 \mathrm{~min}$. In Table 1, lysozyme concentrations for all samples are shown. The ANOVA showed no significant differences in lysozyme concentrations among the samples. Previous studies showed that at $\mathrm{pH} 7$ (i.e., at $\mathrm{pH}$ value of jenny milk), melting temperature of lysozyme is $70^{\circ} \mathrm{C}$ (Venkataramani et al., 2013). As condensation and pasteurization are performed at temperatures less than $70^{\circ} \mathrm{C}$, these thermal treatments did not affect lysozyme concentration, as confirmed by data reported in Table 1 . However, the removal of water during the condensation process could change the protein conformation and deactivate it. Vélez-Ruiza and Barbosa-Cánovas (1998) demonstrated
Table 1. Concentrations $(\mathrm{mg} / \mathrm{L})$ of lysozyme in jenny milk after different thermal treatments

\begin{tabular}{llll}
\hline Sample $^{1}$ & Average & SD & CV \\
\hline RC0 & $1,089.58$ & 2.32 & 0.21 \\
RC40 & $1,088.76$ & 2.51 & 0.23 \\
RC20 & $1,087.66$ & 2.42 & 0.22 \\
PC0 & $1,089.96$ & 2.59 & 0.25 \\
PC40 & $1,090.16$ & 2.65 & 0.24 \\
PC20 & $1,090.05$ & 2.44 & 0.22 \\
\hline
\end{tabular}

${ }^{1}$ Samples are combinations of raw $(\mathrm{R})$ and pasteurized $(\mathrm{P})$ jenny milk at different levels of condensation (C; 0,40 , and $20 \%$ of the initial milk volume).

that the major interactions between milk proteins and the physicochemical changes within components could seriously affect characteristics of milk. To verify the effect of condensation and pasteurization on enzymatic activity, we performed the monitoring of lysozyme antimicrobial activity for every condensation grade of both raw and pasteurized jenny milk according to the protocol described in Materials and Methods.

The results of the antibacterial activity tests are summarized in Figures 2 and 3 against gram-positive and gram-negative bacteria, respectively. The results of the antibacterial activity assays for all studied milk samples showed jenny milk has the most significant activity against $C$. michiganensis, which was equal to the synthetic antibiotics (ampicillin and kanamycin) and higher than the HEW lysozyme solution. Pasteurized milk showed the highest statistically significant inhibition of B. megaterium compared with other milk treatments, but lower than the synthetic antibiotics and equal to HEW lysozyme. In particular, uncondensed pasteurized milk showed the highest antibacterial activity of lysozyme.

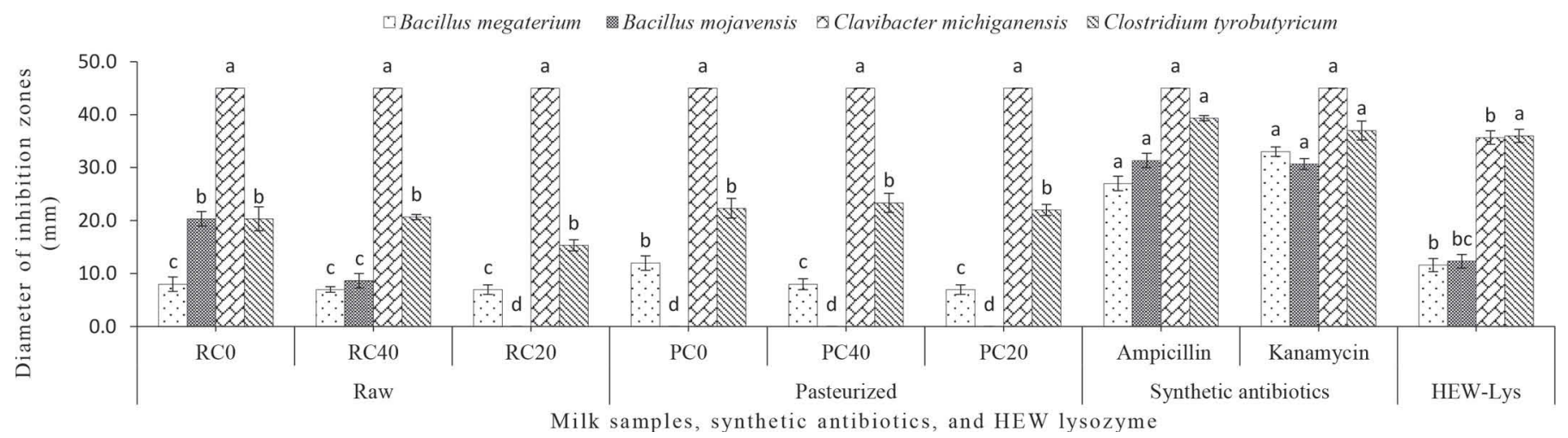

Figure 2. Antibacterial activity of jenny milk against gram-positive bacteria, Bacillus megaterium, Bacillus mojavensis, Clavibacter michiganensis, and Clostridium tyrobutyricum, compared with ampicillin $(100 \mu \mathrm{g} / \mathrm{mL})$, kanamycin $(50 \mu \mathrm{g} / \mathrm{mL})$, and hen egg white lysozyme solution $(1,000 \mathrm{mg} / \mathrm{L})$. Bars with different letters $(\mathrm{a}-\mathrm{d})$ for each bacterium indicate that mean values were significantly different at $P<0.05$ according to Tukey test. Data are expressed as mean of 3 replicates \pm SD. Milk samples are combinations of raw $(\mathrm{R})$ and pasteurized $(\mathrm{P})$ jenny milk at different levels of condensation (C; 0,40 , and $20 \%$ of the initial milk volume). 
The uncondensed pasteurized milk contained lower or no living microorganisms due to the destruction of the raw milk microbial flora through pasteurization; conversely, the raw milk microbial flora was still alive in uncondensed raw samples. These indigenous colonies could have competed with the test microorganisms resulting in a dispersion of enzyme activity of lysozyme. Results also showed no significant differences among the activity of uncondensed raw, RC40, RC20, P40, and P20 in regard to B. megaterium.

Uncondensed raw milk showed the highest significant activity against $B$. mojavensis compared with RC40 and RC20 due to the negative effect on lysozyme activity during the condensation process. Thus, the reduction of antibacterial activity of lysozyme seems directly proportional with increasing the condensation rate. In pasteurized milks, the activity of lysozyme dramatically decreased $(0 \%)$ not only for the condensation process, but also for the high temperatures achieved during pasteurization. Marks et al. (2001) demonstrated that the enzymatic activity of milk proteins could be affected by high temperatures during pasteurization $\left(>72^{\circ} \mathrm{C}\right)$. Our results about antimicrobial activity of jenny milk against B. mojavensis showed that the mild temperatures employed in this study $\left(35^{\circ} \mathrm{C}\right.$ for condensation and $63^{\circ} \mathrm{C}$ for pasteurization) can also affect the enzymatic activity of lysozyme. The 2 tested synthetic antibiotics possessed the highest activity at all against the same bacterium. The HEW-lysozyme solution showed an antimicrobial activity intermediate between uncondensed raw milk and RC40. Conversely, we noted no activity of RC20 and all pasteurized milk treatments against $B$. mojavensis. On the other hand, it should be acknowl- edged that lysozyme may have different inhibitory activity against bacteria (Losso et al., 2000).

The highest significant inhibition of $C$. tyrobutyricum was observed for the 2 synthetic antibiotics and HEW lysozyme solution. No significant difference was observed among all milk (raw and treated) samples. Results of antibacterial activity assays showed that all treatments of the jenny milk have the most significant activity against $X$. campestris compared with the synthetic antibiotics (ampicillin and kanamycin), and no significant differences existed between pasteurized and raw milk activity. Furthermore, no activity was observed against $E$. coli. Antibacterial activity of lysozyme is essentially directed toward gram-positive bacteria. Lysozyme degrades peptidoglycan in the gram-positive bacterial cell wall, leading to rapid killing of these organisms. Gram-negative bacteria, conversely, show a greater resistance to lysozyme because the LPS layer of the outer membrane shields their cell-wall (Nash et al., 2006). Nevertheless, some studies suggest that some gram-positive bacteria show resistance to lysozyme (Masschalck B et al., 2001; Bera et al., 2007), and some gram-negative bacteria are sensitive to this enzyme (Ellison and Giehl, 1991; Pellegrini et al., 1992). In fact, the exact mechanism of lysozyme resistance is not fully understood and may vary according to the bacterial strain or species (Benkerroum, 2008).

Except for B. mojavensis, the lysozyme in jenny milk was active against all gram-positive tested and for $C$. michiganensis the antimicrobial effect was comparable with the synthetic antibiotic action (Figure 2). Moreover, the lysozyme in jenny milk also showed activity against the gram-negative $X$. campestris with the same

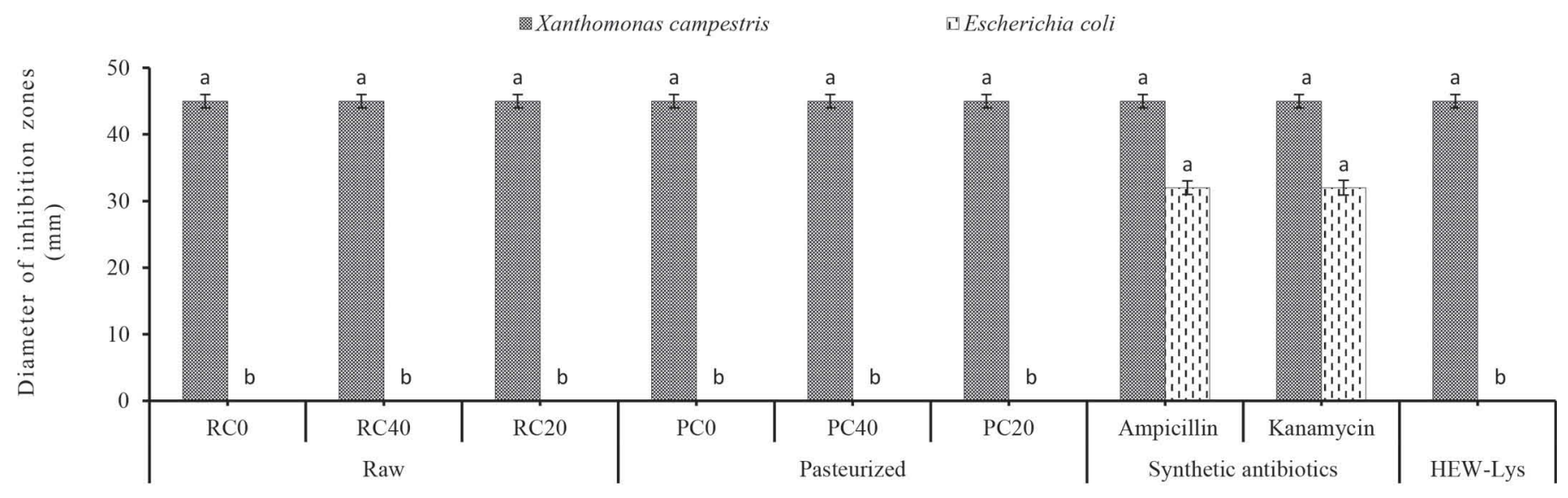

Milk samples and synthetic antibiotics

Figure 3. Antibacterial activity of jenny milk against gram-negative bacteria: Xanthomonas campestris and Escherichia coli compared with ampicillin $(100 \mu \mathrm{g} / \mathrm{mL})$, kanamycin $(50 \mu \mathrm{g} / \mathrm{mL})$, and hen egg white lysozyme solution $(1,000 \mathrm{mg} / \mathrm{L})$ Bars with different letters (a,b) for each bacterium indicate that mean values were significantly different at $P<0.05$ according to Tukey test. Data are expressed as mean of 3 replicates \pm SD. Milk samples are combinations of raw (R) and pasteurized (P) jenny milk at different levels of condensation (C; 0,40 , and $20 \%$ of the initial milk volume). 
level of inhibition seen with the synthetic antibiotics. The high resistance of $E$. coli toward treatments could be due to the presence of LPS in the outer membrane of the E. coli, which make it inherently resistant to external agents, such as hydrophilic dyes, antibiotics, and detergents (Cole et al., 2014). However, the occurrence of gram-negative bacteria naturally sensitive to lysozyme (Ellison and Giehl, 1991; Pellegrini et al., 1992) suggests that LPS may not be the only protective means against lysozyme action, and that other mechanisms, not hindered by LPS, may exist (Monchois et al., 2001; Callewaert et al., 2008). Besides the protective effect of LPS against the hydrolytic action of lysozyme, E. coli bacteria have been shown to use another strategy involving specific protein-inhibitors with high affinity to lysozyme (Monchois et al., 2001).

\section{CONCLUSIONS}

Heating is the major processing treatment applied to milk, both for reduction of the microbial population (pasteurization) and for preparation of milk products (condensation). In this study, we demonstrated that the thermal treatments of pasteurization and condensation do not affect the lysozyme concentration in jenny milk. Concerning its enzyme activity, only B. mojaventis showed resistance to lysozyme in milk samples subjected to heat treatments. Therefore, we can conclude that condensation and pasteurization retain most jenny milk antimicrobial proprieties. Moreover, we showed that lysozyme in jenny milk has antimicrobial activity comparable to synthetic antibiotics against grampositive C. michiganensis and against gram-negative $X$. campestris. The latter is an important finding because, generally, the antibacterial activity of lysozyme is not effective against gram-negative organisms.

\section{ACKNOWLEDGMENTS}

This study was carried out within the project "Equus." The authors thank S. Naturali for his technical support in collection of milk samples.

\section{REFERENCES}

Aloisio, L., D. M. Spera, and M. Terreri. 2011. Production of powder donkey milk. Pages 209-215 in Milk of Donkey: Production, Characteristics and Management of Jennies. Fondazione Iniziative Zooprofilattiche E Zootecniche, Brescia, Italy.

Benkerroum, N. 2008. Antimicrobial activity of lysozyme with special relevance to milk. Afr. J. Biotechnol. 7:4856-4867.

Bera, A., R. Biswas, S. Herbert, E. Kulauzovic, C. Weidenmaier, A. Peschel, and F. Götz. 2007. Influence of wall teichoic acid on lysozyme resistance in Staphylococcus aureus. J. Bacteriol. 189:280283.
Bhunia, A. K., M. C. Johnson, and B. Ray. 1988. Purification, characterization and antimicrobial spectrum of a bacteriocin produced by Pediococcus acidilactic. J. Appl. Bacteriol. 65:261-268.

Bianco, G., C. Labella, A. Pepe, and T. R. I. Cataldi. 2013. Scrambling of autoinducing precursor peptides investigated by infrared multiphoton dissociation with electrospray ionization and Fourier transform ion cyclotron resonance mass spectrometry. Anal. Bioanal. Chem. 405:1721-1732.

Cabral, J. P. 2010. Water microbiology. Bacterial Pathogens and Water. Int. J. Environ. Res. Public. Health. 7:3657-3703.

Callewaert, L., A. Aertsen, D. Deckers, K. G. A. Vanoirbeek, L. Vanderkelen, L. Vanderkelen, B. Masschalck, D. Nakimbugwe, J. Robben, J. M. Van Herreweghe, and C. W. Michiels. 2008. A new family of lysozyme inhibitors contributing to lysozyme tolerance in gram-negative bacteria. PLoS Pathog. 4:e1000019.

Chiavari, C., F. Coloretti, M. Nanni, E. Sorrentino, and L. Grazia. 2005. Use of donkey's milk for a fermented beverage with lactobacilli. Lait 85:481-490.

Cole, E. R., R. B. dos Santos, V. Lacerda, J. D. Martins, S. J. Greco, and A. C. Neto. 2014. Chemical composition of essential oil from ripe fruit of Schinus terebinthifolius Raddi and evaluation of its activity against wild strains of hospital origin. Braz. J. Microbiol. $45: 821-828$

Cosentino, C., C. Labella, M. Musto, R. Paolino, S. Naturali, and P. Freschi. 2015c. Effect of different physical treatments on antioxidant activity of jenny milk. Int. J. Agric. Sci. 5:874-877.

Cosentino, C., R. Paolino, P. Freschi, and A. M. Calluso. 2012. Short communication: Jenny milk production and qualitative characteristics. J. Dairy Sci. 95:2910-2915.

Cosentino, C., R. Paolino, P. Freschi, and A. M. Calluso. 2013. Short communication: Jenny milk as an inhibitor of late blowing in cheese: A preliminary report. J. Dairy Sci. 96:3547-3550.

Cosentino, C., R. Paolino, M. Musto, and P. Freschi. 2015b. Innovative use of jenny milk from sustainable rearing. Pages 113-132 in The Sustainability of Agro-Food and Natural Resource Systems in the Mediterranean Basin. A. Vastola, ed. Springer International Publishing, Cham, Switzerland.

Cosentino, C., R. Paolino, V. Valentini, M. Musto, A. Ricciardi, F. Adduci, C. D'adamo, G. Pecora, and P. Freschi. 2015a. Effect of jenny milk addition on the inhibition of late blowing in semihard cheese. J. Dairy Sci. 98:5133-5142.

del Angel, C. R., and D. G. Dalgleish. 2006. Structures and some properties of soluble protein complexes formed by the heating of reconstituted skim milk powder. Food Res. Int. 39:472-479.

Dugenest, S., J. Combrisson, H. Casabianca, and M. F. Grenier-Loustalot. 1999. Municipal solid waste incineration bottom ash: Characterization and kinetic studies of organic matter. Environ. Sci. Technol. 33:1110-1115.

Ellison, R. T., and T. J. Giehl. 1991. Killing of gram-negative bacteria by lactoferrin and lysozyme. J. Clin. Invest. 88:1080-1091.

Fratini, F., V. V. Ebani, M. Ampola, E. Innocenti, F. Forzale, M. Periccioli, D. Cerri, and E. Andreani. 2006. Determinazione della concentrazione di lisozima in latte ovino normale e mastitico [Evaluation of lysozyme titration in normal and mastitic ewe milk]. Atti XIV Congresso Internazionale Fe.Me. S. P. Rum- Lugo, ed. Universidade de Santiago de Compostela Publicacions, Spain.

Fratini, F., B. Turchi, F. Pedonese, F. Pizzurro, P. Ragaglini, B. Torracca, B. Tozzi, A. Galiero, and R. Nuvoloni. 2015. Does the addition of donkey milk inhibit the replication of pathogen microorganisms in goat milk at refrigerated condition? Dairy Sci. Technol. $8: 1-8$.

Frémont, S., G. Kanny, J. P. Nicolas, and D. A. Moneret-Vautrin. 1997. Prevalence of lysozyme sensitization in an egg-allergic population. Allergy 52:224-228.

Galassi, L., E. Salimei, and M. Zanazzi. 2012. Impiego del latte di asina in sostituzione di lisozima da uovo nella produzione del formaggio duro italiano: Prime esperienze. J. Ital. Dairy Sci. Assoc. 63:73-79.

Gao, A., L. Mutharia, S. Chen, K. Rahn, and J. Odumeru. 2002. Effect of pasteurization on survival of Mycobacterium paratuberculosis in milk. J. Dairy Sci. 85:3198-3205. 
Guarino, C., F. Fuselli, A. La Mantia, and L. Longo. 2011. Development of an RP-HPLC method for the simultaneous determination of benzoic acid, sorbic acid, natamycin and lysozyme in hard and pasta filata cheeses. Food Chem. 127:1294-1299.

King, E. O., M. K. Ward, and D. E. Raney. 1954. Two simple media for demonstration of pyocyanin and fluorescein. J. Lab. Clin. Med. 44:301-307.

La Torre, G. L., M. Saitta, A. G. Potortì, G. Di Bella, and G. Dugo. 2010. High performance liquid chromatography coupled with atmospheric pressure chemical ionization mass spectrometry for sensitive determination of bioactive amines in donkey milk. J. Chromatogr. A 1217:5215-5224.

Ledenbach, L. H., and R. T. Marshall. 2009. Microbiological spoilage of dairy products. Pages 47-67 in Compendium of the Microbiological Spoilage of Foods and Beverages. W. H. Sperber and M. P. Doyle, ed. Springer-Verlag, New York, NY.

León-Sicairos, N., F. López-Soto, M. Reyes-López, D. Godínez-Vargas, C. Ordaz-Pichardo, and M. de la Garza. 2006. Amoebicidal Activity of Milk, Apo-lactoferrin, sIgA and Lysozyme. Clin. Med. Res. 4:106-113.

Lönnerdal, B. 1985. Biochemistry and physiological function of human milk proteins. Am. J. Clin. Nutr. 42:1299-1317.

Losso, J. N., S. Nakai, and E. A. Charter. 2000. Lysozyme. Pages 185-210 in Natural Food Antimicrobial Systems. A. S. Naidu, ed. CRC Press, Boca Raton, FL.

Marks, N. E., A. S. Grandison, and M. J. Lewis. 2001. Challenge testing of the lactoperoxidase system in pasteurized milk. J. Appl. Microbiol. 91:735-741.

Masschalck, B., R. Van Houdt, E. G. Van Haver, and C. W. Michiels. 2001. Inactivation of gram-negative bacteria by lysozyme, denatured lysozyme, and lysozyme-derived peptides under high hydrostatic pressure. Appl. Environ. Microbiol. 67:339-344.

Monchois, V., C. Abergel, J. Sturgis, S. Jeudy, and J. M. Claverie. 2001. Escherichia coli ykfE ORFan. Gene encodes a potent inhibitor of C-type lysozyme. J. Biol. Chem. 276:18437-18441.

Nash, J. A., T. Nicole, S. Ballard, T. E. Weaver, and H. T. Akinbi. 2006. The peptidoglycan-degrading property of lysozyme is not required for bactericidal activity in vivo. J. Immunol. 177:519-526.

Pellegrini, A., U. Thomas, R. von Fellenberg, and P. Wild. 1992. Bactericidal activities of lysozyme and aprotinin against gram-negative and grampositive bacteria related to their basic character. J. Appl. Bacteriol. 72:180-187.

Pellegrino, L., and A. Tirelli. 2000. A sensitive HPLC method to detect hen's egg white lysozyme in milk and dairy products. Int. Dairy J. 10:435-442.
Pérez-Calderón, R., M. A. Gonzalo-Garijo, A. Lamilla-Yerga, R. Mangas-Santos, and I. Moreno-Gaston. 2007. Rercurrent angioedema due to lysozyme allergy. J. Investig. Allergol. Clin. Immunol. 17:264-266.

Polidori, P., and S. Vincenzetti. 2013. Effect of termal treatments on donkey milk nutritional characteristics. Recent Pat. Food Nutr. Agric. 5:182-187.

Raikos, V. 2010. Effect of heat treatment on milk protein functionality at emulsion interfaces. A review. Food Hydrocoll. 24:259-265.

Ribeiro, A. C., and S. D. A. Ribeiro. 2010. Specialty products made from goat milk. Small Rumin. Res. 89:225-233.

Scharfen, E. C., D. A. Mills, and E. A. Maga. 2007. Use of human lysozyme transgenic goat milk in cheese making: Effects on lactic acid bacteria performance. J. Dairy Sci. 90:4084-4091.

Shahani, K. M., W. J. Harper, R. G. Jensen, R. M. Parry Jr., and C. A. Zittle. 1973. Enzymes in Bovine milk: A review. J. Dairy Sci. $56: 531-543$.

Shrivastava, A., and V. B. Gupta. 2011. Methods for the determination of limit of detection and limit of quantitation of the analytical methods. Chron. Young Sci. 2:21-25.

Van Den Berg, J. 1962. Evaporated and condensed milk. Pages 321345 in Milk Hygiene. WHO/FAO, Rome, Italy.

Vélez-Ruiza, J. F., and G. V. Barbosa-Cánovas. 1998. Rheological properties of concentrated milk as a function of concentration, temperature and storage time. J. Food Eng. 35:177-190.

Venkataramani, S., J. Truntzer, and D. R. Coleman. 2013. Thermal stability of high concentration lysozyme across varying $\mathrm{pH}$ : A Fourier Transform Infrared study. J. Pharm. Bioallied Sci. 5:148-153.

Vincenzetti, S., L. Foghini, S. Pucciarelli, V. Polzonetti, N. Cammertoni, D. Beghelli, and P. Polidori. 2014. Hypoallergenic properties of donkey's milk: A preliminary study. Vet. Ital. 50:99-107.

Vincenzetti, S., M. Savini, C. Cecchini, D. Micozzi, F. Carpi, A. Vita, and P. Polidori. 2011. Effects of lyophilization and use of probiotics on donkey's milk nutritional characteristics. Int. J. Food Eng. $7: 1-14$.

Walstra, P., and R. Jenness. 1984. Dairy Chemistry and Physics. John Wiley \& Sons, New York, NY.

Zhang, X. Y., L. Zhao, L. Jiang, M. L. Dong, and F. Z. Ren. 2008. The antimicrobial activity of donkey milk and its microflora changes during storage. Food Contr. 19:1191-1195. 